\title{
BMJ Open Impact of red meat, processed meat and fibre intake on risk of late-onset chronic inflammatory diseases: prospective cohort study on lifestyle factors using the Danish 'Diet, Cancer and Health' cohort (PROCID-DCH): protocol
}

Nathalie Fogh Rasmussen, ${ }^{1,2}$ Katrine Hass Rubin, ${ }^{3}$ Maria Stougaard, ${ }^{3}$ Anne Tjønneland, ${ }^{4}$ Egon Stenager, ${ }^{5,6}$ Merete Lund Hetland, ${ }^{7}$ Bente Glintborg, ${ }^{7,8}$ Anette Bygum, ${ }^{9}$ Vibeke Andersen ${ }^{10,11}$

To cite: Rasmussen NF, Rubin KH, Stougaard M, et al. Impact of red meat, processed meat and fibre intake on risk of late-onset chronic inflammatory diseases: prospective cohort study on lifestyle factors using the Danish 'Diet, Cancer and Health' cohort (PROCIDDCH): protocol. BMJ Open 2019;9:e024555. doi:10.1136/ bmjopen-2018-024555

- Prepublication history for this paper is available online. To view these files, please visit the journal online (http://dx.doi. org/10.1136/bmjopen-2018024555).

Received 1 June 2018 Revised 8 December 2018 Accepted 18 February 2019

Check for updates

(C) Author(s) (or their employer(s)) 2019. Re-use permitted under CC BY-NC. No commercial re-use. See rights and permissions. Published by BMJ.

For numbered affiliations see end of article.

Correspondence to Professor Vibeke Andersen; vandersen@health.sdu.dk

\section{ABSTRACT}

Introduction Chronic inflammatory diseases (CIDs) (Crohn's disease, ulcerative colitis, psoriasis, psoriatic arthritis, rheumatoid arthritis and multiple sclerosis) are diseases of the immune system that have some shared genetic and environmental predisposing factors, but still few studies have investigated the effects of lifestyle on disease risk of several CIDs. The primary aim of this prospective cohort study is to investigate the impact of fibre, red meat and processed meat on risk of late-onset CID, with the perspective that results of this study can contribute in supporting future diet recommendations for effective personalised prevention.

Methods and analysis The study will use data from 57053 persons from the prospective Danish cohort study 'Diet, Cancer and Health' together with National Health Registry data. The follow-up period is from December 1993 to December 2018. Questionnaire data on diet and lifestyle were collected at entry to the Diet, Cancer and Health study. The outcome CID is defined as having a diagnosis of one of the CIDs registered in the National Patient Registry or, for multiple sclerosis, in the Danish Multiple Sclerosis Registry during follow-up and being treated with a drug used for the specific disease. The major outcome of the analyses will be to detect variability in risk of late onset of any CID and, if power allows, disease risk of late onset of each CID diagnosis between persons with different fibre and red meat, and processed meat intake. The outcome will be adjusted for age, sex, body mass index, physical activity, energy, alcohol, fermented dairy products, education, smoking status, hormone replacement therapy and comorbidity. Ethics and dissemination The study is approved by the Danish Data Protection Agency (2012-58-0018). The core study is an open register-based cohort study. The study does not need approval from the Ethics committee or Institutional Review Board by Danish law. Study findings will be disseminated through peer-reviewed journals, patient associations and presentations at international conferences.
Strengths and limitations of this study

The linkage to Danish national registers will ensure almost complete follow-up of the study population, as the Danish registries are considered of high validity and completeness.

- The big sample size will enable a sufficient power of the total late-onset chronic inflammatory disease (CID) group even when taking loss to emigration and competing risk of death into account.

- The study includes several CIDs.

- Risk of low specificity of the diagnostic codes and treatment codes as criteria for identifying late-onset CID cases.

- Prospective studies including younger age groups are necessary to reveal the generalisability of the results.

Trial registration number NCT03456206; Post-results.

\section{INTRODUCTION}

The chronic inflammatory diseases (CIDs) can be considered as systemic diseases which primarily affect one organ such as the intestine (inflammatory bowel disease [IBD]: Crohn's disease $[\mathrm{CD}]$ and colitis ulcerosa $[\mathrm{UC}]$ ), skin (psoriasis [PsO]), joints (rheumatoid arthritis [RA] and psoriatic arthritis $[\mathrm{PsA}]$ ) or the brain (multiple sclerosis [MS]).

The peak of disease onset is in the adult phase of life. The diseases have a large impact on the patients and their families' quality of life due to lack of causative treatment, and on the society due to the absence from work and on healthcare economy due to lack of preventative measures. ${ }^{1-7}$ The CIDs have a high 
prevalence, with IBD and MS affecting, respectively, $0.5 \%$ and $0.1 \%$ of the population in the Western world. ${ }^{8-12}$ Studies from across the world have reported prevalence estimates of $\mathrm{RA}$ and $\mathrm{PsO}$ ranging from $0.3 \%$ to $1.0 \%$ and $0.7 \%$ to $3.2 \%$, respectively, ${ }^{2813-15}$ while the prevalence of PsA is estimated as $0.04 \%-0.25 \%$ across countries. ${ }^{14} 16$ Furthermore, one-third of patients with RA are diagnosed at $>60$ years of age ${ }^{17}$ and the incidence of late-onset IBD and MS has been reported to increase. ${ }^{18} 19$

The CIDs have some shared genetic ${ }^{20-24}$ and environmental (eg, smoking, gut microbiome) predisposing factors, and causes of the high incidence and prevalence point to such environmental factors. ${ }^{8}{ }^{25-40}$ Therefore, further research of the associations between potential modifiable environmental risk factors and risk of CID is important.

\section{Evidence-based research}

It has been demonstrated that a high level of red meat consumption is a risk factor for the development of inflammatory polyarthritis (including RA).$^{39} 40$ A high-fibre intake has been associated with low risk of IBD. ${ }^{27}$ Furthermore, several studies of the impact of dietary factors on MS point towards an impact of meat preservation such as smoking or addition of nitrites. ${ }^{41-44}$ Studies have also suggested other lifestyle factors such as physical activity, ${ }^{45-47}$ body mass index (BMI), ${ }^{147-49}$ smoking status $^{50-56}$ and other dietary factors such as alcohol, ${ }^{157-59}$ dairy products ${ }^{38}$ and glycaemic index ${ }^{6061}$ to be associated with CIDs. Furthermore, studies have shown that the interactions among the microbiota, female sexual hormones and immunity are associated with the development of autoimmune diseases. ${ }^{62}$

There are many potential mechanisms whereby the environment such as diet may affect the immune system (figure 1). Recently, we provided the hypothesis that intake of high fibre/low red and processed meat may protect against CID. ${ }^{61}$ Figure 1 presents a model, proposed in a previous study, ${ }^{8}$ whereby a diet high in meat and low in fibres may impact inflammation.

\section{Aims and hypotheses}

Based on previous evidence, we set out to prospectively identify dietary factors that have an impact on disease risk of late-onset CID.

The primary aim of this prospective cohort study is to investigate the impact of fibre, red meat and processed meat on disease risk outcomes of late-onset CID in the

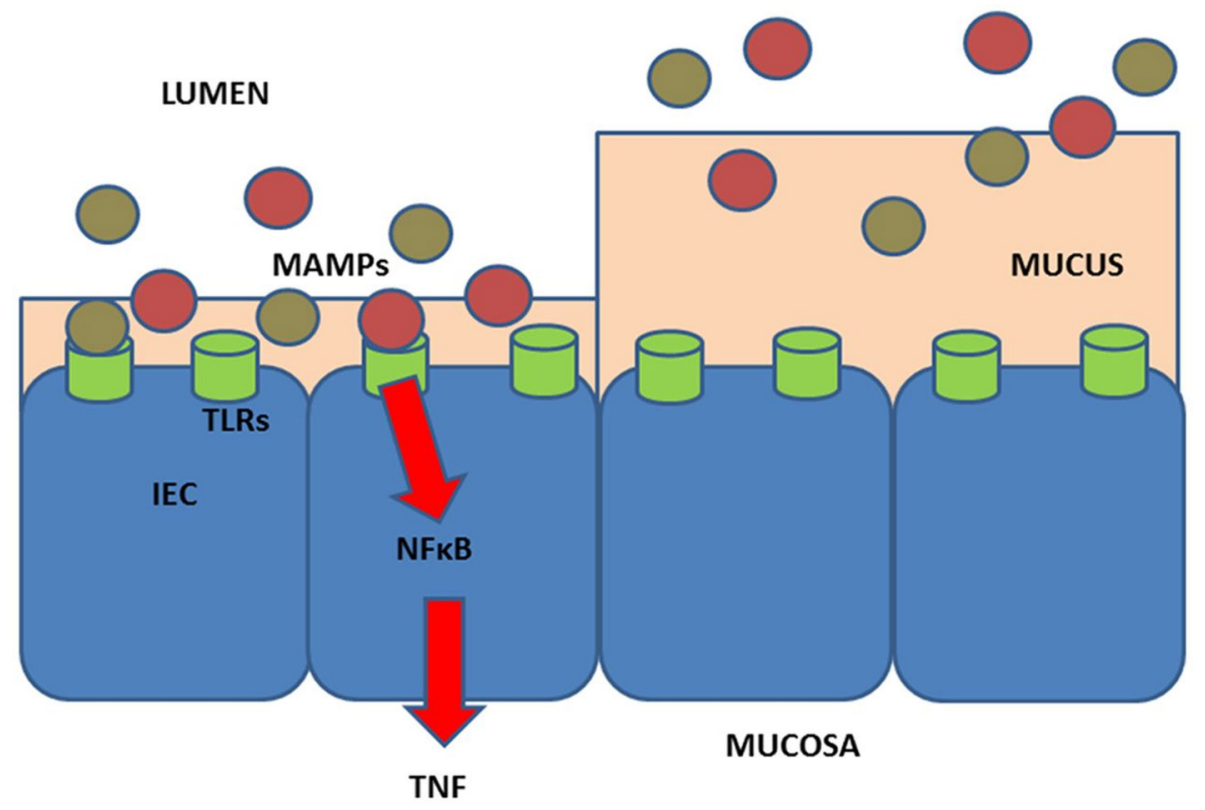

Figure 1 Hypothesis for effects of diet in relation to the development of chronic inflammatory diseases (CIDs). Diet (meat, ${ }^{97}$ fibre, ${ }^{97}$ animal fat, ${ }^{98} \mathrm{n}-3^{30}$ and $\mathrm{n}-6$ polyunsaturated fatty acids, vitamins $A^{99}$ and $D,{ }^{100}$ carotenoids, ${ }^{101}$ smoking, gluten ${ }^{102}$ ) may affect the immune system ${ }^{103} 104$ either directly or indirectly via, for example, the activity and composition of the gut microbiome. ${ }^{105} 106$ The effect of low intake of fibre/high intake of red and processed meat is shown at left: in short, low intake of fibre (which could otherwise serve as a nutrient for the microbes) may lead to the microbial metabolism of mucus and to decrease of the intestinal mucus layer. ${ }^{61} 107108$ A high intake of red and processed meat may render the mucus layer penetrable to, for example, bacteria by reducing the disulphide bonds in the mucus network. ${ }^{8105} 109$ Thus, microbes may reach the epithelium ${ }^{8110111}$ and activate the immune system. ${ }^{8112113}$ There is some support for such a mechanism in CIDs, ${ }^{8}$ including findings of; high amounts of sulphate-reducing bacteria in patients with inflammatory bowel disease (IBD) ${ }^{8111} 114$; association of high-fibre intake with low risk of IBD among 170776 participants from the prospective Nurses' Health Study I ${ }^{827}$; and association of high intake of red meat and total protein and risk of developing inflammatory polyarthritis in the population-based prospective cohort of 25630 participants from the European Prospective Investigation of Cancer in Norfolk. ${ }^{839} 40$ IEC, intestinal epithelial cell; MAMPs, microbe-associated molecular patterns; NFkB, nuclear factor kappa-light-chain-enhancer of activated B cells; TLRs, toll-like receptors; TNF, tumor necrosis factor. Figure from Christensen et al ${ }^{8}$ (copyright 2018 by Vibeke Andersen). 
'Diet, Cancer and Health' (DCH) cohort. The overall perspectives are that results from this study will be contributing in supporting future diet recommendations for effective personalised prevention of individuals identified to be at high risk.

The main hypothesis is that 'the risk of late-onset CID will be significantly lower among those with a high fibre/ low red meat, and processed meat intake compared with those with a low fibre/high red meat and processed meat intake.' The hypothesis is illustrated in figure 1.

Based on previous research on a shared aetiology in CIDs, we hypothesise that 'the suggested association between high fibre/low red meat, and processed meat intake and risk of developing CID is applicable for each of the CID diagnoses'.

The secondary aim of this prospective cohort study is to investigate whether risk of late-onset CID in the DCH cohort is affected by other dietary and lifestyle differences, and therefore to adjust for the potential confounders: age, sex, BMI, physical activity, energy, alcohol intake, intake of fermented dairy products, education after basic school, hormone replacement therapy (HRT), smoking status and comorbidity.

\section{METHODS AND ANALYSES \\ Design and setting}

This study is an observational study using prospective registry follow-up data. We will use the Danish cohort 'DCH', and the follow-up period will be from the date of entry in the DCH cohort (between December 1993 and May 1997) until December 2018.

The DCH study is an ongoing Danish cohort study designed to investigate the relation between diet, lifestyle and disease risk. ${ }^{63}$ The cohort consists of 57053 persons, recruited between December 1993 and May 1997. All the subjects (50-64 years of age) gave detailed information on diet (Food Frequency Questionnaire [FFQ]) and other lifestyle data. Questionnaire data on diet and lifestyle were collected at study entry. ${ }^{63}$ Data from the DCH cohort will be combined with Danish health registries (the National Patient Registry [NPR], the Danish Civil Registration System [CRS], The Danish National Prescription Registry [DNPR] and the Danish Multiple Sclerosis Registry [DMSR]).

\section{Participant characteristics and eligibility criteria}

Criteria for inclusion: the population to be studied include participants in the DCH cohort. ${ }^{63}$ In short, the criteria for invitation to the DCH cohort were: age between 50 and 64, born in Denmark, and no diagnosis of cancer registered in the Danish Cancer Registry. All persons fulfilling these criteria and living in the areas of Copenhagen and Aarhus were invited. ${ }^{63}$

Criteria for exclusion: participants registered in NPR or DMSR with a CID primary diagnosis from a department with relevant area of specialisation in the period between 1977 and entry to the DCH cohort will be excluded regardless of whether the person receive medical treatment for CID or not.

\section{The Danish health registries}

We will extract data from the four national registries in those time periods that is possible for each registry: NPR from 1977 to 2018, CRS from 1977 to 2018, DNPR from 1994 to 2018 and DMSR from 1977 to 2018. An overview of the information obtained from the different registries is presented in table 1 .

The NPR will be used to identify patients with CID during follow-up and, in addition, patients with CID before study entry. The NPR contains data on all patients admitted to Danish hospitals since 1977. The register covers both inpatient and outpatient records and indicates the main medical reason for diagnostic procedures

\begin{tabular}{|c|c|c|c|}
\hline Variable & Definition & Registry & Time period \\
\hline CPR & Civil Registration Number & CRS & $1977-2018$ \\
\hline ICD-10 code* & International Classification of Diseases & NPR & 1994-2018 \\
\hline ICD-8 code* & International Classification of Diseases & NPR & $1977-1993$ \\
\hline Medication (ATC code) & $\begin{array}{l}\text { Anatomical Therapeutic Chemical classification } \\
\text { (ATC) code }\end{array}$ & DNPR & 1994-2018 \\
\hline Treatment code & Medical treatment classification code & NPR & 1994-2018 \\
\hline $\begin{array}{l}\text { Department with relevant area of } \\
\text { specialisation }\end{array}$ & $\begin{array}{l}\text { Medical and gastroenterological department } \\
\text { (IBD), medical and rheumatological department } \\
\text { (RA, PsA), Medical and dermatological } \\
\text { department (PsA, PsO) }\end{array}$ & NPR & $1977-2018$ \\
\hline $\begin{array}{l}\text { ICD-8 and ICD-10 codes for multiple } \\
\text { sclerosis (MS) }\end{array}$ & Diagnostic codes for MS & DMSR & $1977-2018$ \\
\hline
\end{tabular}

${ }^{*}$ ICD-8 and ICD-10 codes in the period 1977-1997 will be used to define chronic inflammatory disease diagnosis.

CRS, The Danish Civil Registration System; DMSR, Danish Multiple Sclerosis Registry; DNPR, Danish National Prescription Registry;

IBD, inflammatory bowel disease; NPR, National Patient Registry; PsA, psoriatic arthritis; PsO, psoriasis; RA, rheumatoid arthritis. 
or treatment (since 1971 according to the eight version and 1994 according to the tenth version of the International Classification of Diseases [ICD-8 and ICD-10]). ICD-8 and ICD-10 codes will be used to identify cases diagnosed before entry to the DCH cohort study. Information on the departments with the relevant areas of specialisation will be obtained from the NPR and used to identify cases as described in the Data analysis section.

The DMSR will be used to identify patients with MS during follow-up, and in addition, patients with MS before study entry.

The DNPR will be used to obtain information on the medical treatment according to the Anatomical Therapeutic Chemical classification (ATC) code.

From the CRS, we will extract follow-up information on civil status, death and immigration.

Data will be linked by the unique identification number assigned to all residents in Denmark at birth or first immigration which provides a unique opportunity to link information about diagnoses, medications, etc., at the individual level.

\section{Outcome and exposures}

Outcome: in this study, the outcome late-onset CID is defined as one of the following diseases: $\mathrm{CD}, \mathrm{UC}, \mathrm{PsO}$, PsA, RA or MS. This outcome is defined by fulfilling the following two criteria: (1) having the CID disease in NPR (except MS) from a department with relevant area of specialisation, or in the DMSR (MS) during the follow-up period and (2) being treated (irrespective of the number of treatments) with a drug used for the specific disease, and the treatment being registered either in the DNPR or from a department with relevant area of specialisation (criterion 2 will not apply to MS). The outcome late-onset CIDs with the associated ICD-8 and ICD-10 codes and the ATC codes in DNPR and treatment codes in the NPR are specified in table 2. The date and year of the diagnosis are defined as the date and year of the diagnosis in NPR

Table 2 Specification of outcome chronic inflammatory diseases (CIDs) with associated diagnostic code and treatment codes

\begin{tabular}{|c|c|c|c|c|c|}
\hline \multirow[b]{2}{*}{ CID } & \multicolumn{2}{|c|}{ Diagnostic code (NPR) } & \multicolumn{2}{|c|}{$\begin{array}{l}\text { Medical treatment (DNPR and } \\
\text { NPR) }\end{array}$} & \multirow{2}{*}{$\begin{array}{l}\text { Department with } \\
\text { relevant area of } \\
\text { specialisation }\end{array}$} \\
\hline & ICD-8* & ICD-10 & $\begin{array}{l}\text { ATC code } \\
\text { (DNPR)† }\end{array}$ & $\begin{array}{l}\text { Treatment code } \\
\text { (NPR)† }\end{array}$ & \\
\hline Crohn's disease (CD) & $\begin{array}{l}563.00,563.02, \\
563.08 \\
563.09 \\
563.91\end{array}$ & K50.0-50.9 & $\begin{array}{l}\text { L04AB02 } \\
\text { L04AB04 } \\
\text { L04AB06 } \\
\text { L04AB05 }\end{array}$ & $\begin{array}{l}\text { BOHJ18A1 } \\
\text { BOHJ18A3 } \\
\text { BOHJ18A4 } \\
\text { BOHJ18A5 }\end{array}$ & $\begin{array}{l}\text { Gastroenterology, } \\
\text { internal medicine }\end{array}$ \\
\hline $\begin{array}{l}\text { Chronic polyarthritis, } \\
\text { including RA }\end{array}$ & $\begin{array}{l}712.19,712.29 \\
712.39,712.59\end{array}$ & M05.9, M06.0 & $\begin{array}{l}\text { L04A×01 } \\
\text { L04A } \times 03 \\
\text { L04AA13 } \\
\text { P01BA02 }\end{array}$ & $\begin{array}{l}\text { BWHA115 } \\
\text { BLHM2 } \\
\text { BWHB83 } \\
\text { BOHJ18 }\end{array}$ & $\begin{array}{l}\text { Rheumatology, internal } \\
\text { medicine }\end{array}$ \\
\hline Multiple sclerosis (MS) & 734.0-9‡ & G35.9‡ & Not used & Not used & $\begin{array}{l}\text { Danish Multiple } \\
\text { Sclerosis } \\
\text { Registry (DMSR) }\end{array}$ \\
\hline
\end{tabular}

*International Classification of Disease (ICD)-8 and ICD-10 codes will be used to define participants with a CID diagnosis.

†These Anatomical Therapeutic Chemical classification (ATC) and treatment codes for CD and UC are used by the Danish National Registry for Biological Therapy in Inflammatory Bowel Disease. ${ }^{98}$

¥ICD-8 and ICD-10 codes for MS will be extracted from the DMSR.

DNPR, Danish National Prescription Registry; NPR, National Patient Registry; RA, rheumatoid arthritis. 
and/or DMSR. If a patient has several CID diseases, only time to the first diagnosis will be included in the analyses.

Exposure and possible confounders: information on exposure in this study is defined as high-fibre intake and high red meat, and processed meat intake, and also other dietary and lifestyle factors.

In the DCH study, information on diet and lifestyle exposure was collected at enrolment using questionnaires as has been described in detail elsewhere. ${ }^{63}$ In short, in the FFQ diet consumption was assessed in 12 categories of predefined responses, ranking from 'never' to 'eight times or more per day over the past 12 months'. The daily intake was then calculated by FoodCalc. ${ }^{63}$ Both intake of dietary fibre and red meat and processed meat were measured as continues variable in $\mathrm{g} /$ day. The initially collected data on diet and lifestyle exposure of the DCH cohort is used as the baseline information on exposure in this study.

Information on dietary and lifestyle exposures used for this study is specified in table 3. Fibres, red meat and processed meat are defined based on the classification of the food items in the DCH study, ${ }^{63}$ and with inspiration from other studies using dietary data from the DCH cohort. ${ }^{64-66}$ Red meat is defined as fresh and minced meat (unprocessed) from beef, veal, pork and lamb and excluding poultry, fish and eggs. Processed meat consists of red meat, poultry and fish items that have undergone processing such as smoking, salting or curing. This includes various kinds of sausages, salami, smoked or cooked ham, poultry or fish, other cold cuts, bacon and liver pate. Poultry includes chicken and turkey both unprocessed and processed, such as various cold cuts of chicken and turkey. Fish includes all unprocessed and processed fish as well as shellfish. Total meat is defined as the total of red (unprocessed) meat, red processed meat together with poultry and fish. ${ }^{64-66}$ Fibres are defined as fibres from fibrous food items from the FFQ.

Information on possible confounders will also be obtained from the questionnaire data at enrolment in relation to sex, age, education after basic school, BMI, physical activity, energy, HRT, comorbidity, smoking status, alcohol intake and also intake of fermented dairy products. The Charlsons Comorbidity Index ${ }^{67}$ will be used to classify comorbidity among the study participants. ICD-8 and ICD-10 codes from the NPR will be used to calculate the Charlson score, using the updated Charlson Comorbidity Index. ${ }^{68}$

Primary exposure variable: the primary exposure variables will be analysed in tertiles. Based on the hypothesis that the risk of CID and late-onset CID will be lower among those with a high fibre/low red meat, and processed meat intake compared to those with a low fibre/high red meat, and processed meat intake, it is expected that

- The upper tertile of the sample (33.3\% of the total sample), based on the ratio of fibre/meat intake, is associated with lower risk of CID and late-onset CID.

- The lower tertile of the sample $(33.3 \%$ of the total sample) with respect to intake of red meat and
Table 3 Specification of exposures and overall food groups and lifestyle factors

\begin{tabular}{|c|c|}
\hline Variable & Definition (unit) \\
\hline \multicolumn{2}{|l|}{ Diet } \\
\hline Total energy intake & kJ/day \\
\hline Total meat & g/day \\
\hline Red meat & g/day \\
\hline Red, processed meat & g/day \\
\hline Fish (fresh and processed) & g/day \\
\hline Poultry (fresh and processed) & g/day \\
\hline Total dietary fibre intake & g/day \\
\hline Legumes & g/day \\
\hline Vegetables & g/day \\
\hline Fruits & g/day \\
\hline Cereals & g/day \\
\hline Dairy products & g/day \\
\hline \multicolumn{2}{|l|}{ Lifestyle factors } \\
\hline Alcohol intake & Units of alcohol/week* \\
\hline Smoking status & Yes/no \\
\hline \multicolumn{2}{|l|}{ Former smoker } \\
\hline \multicolumn{2}{|l|}{ Current smoker } \\
\hline \multicolumn{2}{|l|}{ Never smoker } \\
\hline $\begin{array}{l}\text { Metabolic equivalent of task (MET) } \\
\text { score (physical activity) }\end{array}$ & hours/week \\
\hline Body mass index & $\mathrm{kg} / \mathrm{cm}^{2}$ \\
\hline $\begin{array}{l}\text { Highest education after basic } \\
\text { school }\end{array}$ & Yes/no \\
\hline \multicolumn{2}{|l|}{ Vocational education } \\
\hline \multicolumn{2}{|l|}{ Higher education 1-2 years } \\
\hline \multicolumn{2}{|l|}{ Higher education 3-4 years } \\
\hline \multicolumn{2}{|l|}{ Higher education $>4$ years } \\
\hline $\begin{array}{l}\text { Comorbidity (Charlson } \\
\text { Comorbidity Index) }\end{array}$ & Index score \\
\hline Hormone replacement therapy & Yes/no \\
\hline
\end{tabular}

${ }^{*}$ One unit of alcohol is defined as $12 \mathrm{~g}$ of pure alcohol.

processed meat and the upper tertile of the sample (33.3\% of the total sample) with respect to intake of dietary fibres are independently associated with lower risk of CID and late-onset CID, and a potential interaction between them may further lower the risk of CID and late-onset CID.

Other (exploratory) exposure variables:

- Other dietary and lifestyle factors independently or combined will be analysed, and are presented in table 3.

\section{Statistical analysis plan}

The data obtained from this study will be used to investigate our ability to predict risk of late-onset CID, based on whether a diet high in fibre and low in red meat, and 
processed meat is a predictive factor. Furthermore, data on other lifestyle factors and dietary factors obtained from the FFQ will be used to investigate whether these factors potentially could give rise to confounding of the association between fibre/meat intake and risk of lateonset CID.

Descriptive analyses for categorical variables will be presented as frequencies, and differences between lateonset CID cases and non-cases will be evaluated by $\chi^{2}$ test. Continuous variables will be tabulated as medians (with quartiles, Q1 and Q3) and non-parametric tests on the equality of medians will be used to test for differences between groups. $\mathrm{P}$ values below 0.05 will be considered statistically significant. Negative binomial regression will be applied to calculate incidence rates per 1000 patient years and incidence rate ratios between exposures. To investigate the risk of and time to CID diagnosis, the FineGray competing risk regression model will be applied, and thus competing risk of death will be taken into account while handling emigration as censoring and reporting cumulative incidences and sub-HRs and the corresponding $\mathrm{p}$ values for late-onset CID associated with specified food substitutions. Regressions will be carried out as both crude regressions, only including the exposure, and adjusted for age, sex, lifestyle factors and selected comorbidities. Sensitivity analyses of the outcome variable and use of medication will be carried out.

Logistic regression will be conducted to examining the association between fibre/meat intake and already being diagnosed with a CID diagnose. Analyses will be conducted using Stata V.15. ${ }^{69}$

If power of each of the disease groups allows, there will be conducted subanalyses on each of the late-onset CID diagnoses separately with the overall aim of testing if the hypothesised association between diet factors and development of late-onset CID is applicable for all the lateonset CIDs or if some of the late-onset CIDs deviate from this association. Moreover, analyses omitting MS from the overall definition of CID will be performed.

Information on the departments with the relevant areas of specialisation will be used to evaluate the robustness of the diagnosis codes from the NPR and to identify the cases as we will only accept cases that have a diagnosis from a relevant department. The DMSR is highly validated, ${ }^{70}$ and data from the registry will be used to ensure complete follow-up of valid diagnoses of MS.

Power considerations, late-onset CID: the age-adjusted (age between 45 and 69) incidences per 100000 years of the CIDs in Denmark are 10.1-10.6 for $\mathrm{CD}^{71}$; 27.5-32.7 for $\mathrm{UC}^{71}$; 200-225 for $\mathrm{PsO}^{15}$; $28-35$ for $\mathrm{PsA}^{16}$; 4.4-7.5 for $\mathrm{MS}^{19}{ }^{72-75}$ and $28.1-57.6$ for RA. ${ }^{76}$ In the cohort of approximately 57000 participants and a follow-up period of approximately 20 years, these incidences correspond to an estimate of approximately 2000 cases of CID in the cohort. To estimate the power of the study, we therefore expect approximately 2000 cases of CID, that is, an incidence of about $3 \%$ and about one-third of the cohort in the low risk and two-thirds in the high-risk exposure.
Assuming a fixed follow-up of 20 years and a relevant effect size of $2 \%$ CID risk in the low-risk exposure compared with $3 \%$ in the high-risk exposure, this would require 11667 participants to obtain a power of 0.90 in an (unadjusted) $\chi^{2}$ test. Hence, with a total cohort size of approximately 57000 , this should ensure a sufficient power even when taking loss to emigration and competing risk of death (resulting in less than 20-year follow-up for some participants) into account.

\section{Patient and public involvement}

This study is register based and there will be no patients or public involvement in the study.

\section{Strengths and limitations of the study}

A strength of this study is that it is not limited to one disease, as it includes several CIDs. Another strength is that the linkage to Danish health registries will ensure almost complete follow-up of the study population, as the Danish health registries are considered the internationally most comprehensive with high validity ${ }^{78-81}$ Furthermore, in this study, we have chosen very restrictive criteria for defining the late-onset CID cases by requiring that cases fulfil both diagnostic and treatment criteria, or that the cases were registered in the DMSR. This approach ensures that a high proportion of the identified cases really had late-onset CID. Therefore, some 'real' CID cases might not have been identified, hence lowering the sensitivity. ${ }^{70} 8283$

A possible limitation of this study could have been the validity of the diagnostic codes from the NPR and the treatment codes from the DNPR as criteria for identifying late-onset CID cases. ${ }^{70} 82$ But, as described in the analysis plan, this potential limitation will be sought eliminated by using the information on the hospital departments, and for MS, using the DMSR for identifying MS cases. In addition, usually dietary habits do not change much during life. Therefore, the exposure time to the diet is long in $50+$ age group and a possible impact of diet is possibly located much earlier in life. Therefore, we have included an analysis among those who at entry to the DCH cohort already had a CID diagnosis to examine if their low/high intake of dietary fibre, red meat and processed meat is associated with having CID. We are well aware that such an analysis might be impacted by bias by indication and that the results should be interpreted with this in mind.

The FFQ applied in the present study has been used in the large, European prospective cohort study 'The European Prospective Investigation into Cancer and Nutrition' (EPIC) ${ }^{84} 85$ and it has been used and evaluated in the Danish population, with results that demonstrate consistency. ${ }^{86-88}$ However, the FFQ is not without limitations, with respect to the lack of information on portion sizes $^{89}{ }^{90}$ or to underestimation and overestimation of intake of unhealthy and healthy food. ${ }^{91}$ Any imprecision of the FFQ due to standardised portion sizes or incorrect reporting of food intake, will lead to large CIs, which potentially can lead to null results. ${ }^{8}$ On the other hand, 
studies suggest that specification of a standard portion size may not introduce a large error in the estimation of food and nutrient intake. ${ }^{92}$ Furthermore, the FFQ has been validated as being appropriate for use in studies that examine relationships between diet and risk of disease. ${ }^{91}$

Another limitation of this study is the validity of the information on exposure as this information is collected at study entry, which potentially can be several years before any outcome appears, and measurement error in the FFQ may occur if the participants change their diet over time. Furthermore, there is a potential risk of recall bias according to the information on exposure, as this information relies on the participants' ability to recall their dietary intake. In this study, however, it is expected that dietary and lifestyle patterns among adults are relatively stable over time, based on other longitudinal studies that showed minimal temporal changes. ${ }^{9394}$

The MET score is an accepted standard measure of physical activity. ${ }^{95}$ However, the weaknesses of the MET score include a risk of adding random variation by applying an assumed intensity to include activities. Another weakness of the MET score is the implicit assumption that the intensity aspect of physical activity is important for the development of disease. ${ }^{95}$

The study population in this study is based on a cohort of middle-aged women and men living in urban areas. This could reduce the generalisability of study findings, as the incidence of CID diagnoses could be different for younger persons and persons from rural areas.

The disease groups may be heterogeneous regarding dietary and lifestyle factors. This study may not capture every dietary and lifestyle difference between the disease groups, due to insufficient power of each disease group, as described in the analysis plan. Replication of the results in other well-characterised populations using prospectively sampled dietary data will minimise the risk of potential type 2 errors. Study results should preferably be replicated in cohorts in other countries and other age groups for further evaluation of the robustness of the results.

\section{Project organisation}

This registry study is a cross-disciplinary collaboration that includes clinical specialists within neurology, dermatology, rheumatology, IBDs, prospective cohort study design and clinical registries.

\section{Perspectives}

We anticipate that the PROCID-DCH study will reveal factors of importance, including whether the diet is likely to interfere with the disease risk of late-onset CID.

The perspective is that significant results from this study will be sought replicated in other cohorts such as the EPIC-IBD ${ }^{84}$ and UK biobank ${ }^{96}$ with high-quality prospective lifestyle data. Successful replication indicates the robustness of the findings which is an important step on the road to developing clinical tools for effective personalised prevention of individuals at high risk.

\section{Dissemination of results to the public and scientifically}

Target journals include international journals within internal medicine. In addition to the scientific reporting of results, major findings with translational implications will also be communicated to categories of both health professionals, and targeted stakeholders including public health policy-makers, and to the general public through various media and news activities. Intellectual Property Rights to discoveries based on the outlined research belong to the University of Southern Denmark.

\section{Author affiliations}

${ }^{1}$ Faculty of Health Sciences, Aarhus University, Aarhus, Denmark

${ }^{2}$ Focused Research Unit for Molecular Diagnostic and Clinical Research, IRS-Center Sonderjylland, Hospital of Southern Jutland, Aabenraa, Denmark

${ }^{3}$ OPEN - Odense Patient Data Explorative Network, Department of Clinical Research, University of Southern Denmark, and Odense University Hospital, Odense, Denmark ${ }^{4}$ Diet, Genes and Environment, Danish Cancer Society Research Center,

Copenhagen $\emptyset$, Denmark/Department of Public Health, Faculty of Health and Medical Sciences, University of Copenhagen, Copenhagen, Denmark

${ }^{5}$ Department of Regional Health Research, University of Southern Denmark, Odense, Denmark

${ }^{6}$ The Multiple Sclerosis Clinic of Southern Jutland (Sonderborg, Kolding, Esbjerg), Department of Neurology, Hospital of Southern Jutland, Sonderborg, Denmark ${ }^{7}$ DANBIO Registry/Copenhagen Center for Arthritis Research (COPECARE), Center for Rheumatology and Spine Diseases, Centre of Head and Orthopaedics, Rigshospitalet Glostrup, Glostrup, Denmark

${ }^{8}$ Department of Rheumatology, Gentofte Hospital, Hellerup, Hovedstaden, Denmark ${ }^{9}$ Department of Dermatology and Allergy Centre, Odense Universitetshospital, Odense, Denmark

${ }^{10}$ Focused Research Unit for Molecular Diagnostic and Clinical Research, Hospital of Southern Jutland, Aabenraa, Denmark

${ }^{11}$ institute og molecular medicine, Syddansk Universitet Det

Sundhedsvidenskabelige Fakultet, Odense, Denmark

Contributors VA conceived the presented idea and achieved funding. AT (diet and environmental factors, epidemiology) designed the cohort, collected the data and made the data available for the present project. NFR, KHR, MS and VA wrote the first draft and contributed to the further preparation and final adjustments of the protocol. According to their respective specialisation, all other authors, ES (multiple sclerosis), MLH (rheumatology), BG (rheumatology) and AB (psoriasis) contributed to the project. All authors discussed the results and contributed to the final manuscript.

Funding This work is supported by Region of Southern Denmark grant number [17/33849] (Vibeke Andersen), and the Danish Rheumatism Association (R150A4434-B760, Vibeke Andersen).

Competing interests $B G$ declares to have received research funding from Abbvie, Biogen, Pfizer. MLH declares to have received research funding from BMS, MSD, Pfizer, Biogen, Samsung, CellTrion, Lilly and Novartis. AB has participated in the development of educational material for Biogen. All other authors declare no conflict of interest.

\section{Patient consent for publication Obtained.}

Ethics approval This is an open register-based cohort study. The study does not need approval from the local Ethics committee or Institutional Review Board by Danish law. The study was approved by the Danish Data Protection Agency (2012-58-0018).

Provenance and peer review Not commissioned; externally peer reviewed.

Open access This is an open access article distributed in accordance with the Creative Commons Attribution Non Commercial (CC BY-NC 4.0) license, which permits others to distribute, remix, adapt, build upon this work non-commercially, and license their derivative works on different terms, provided the original work is properly cited, appropriate credit is given, any changes made indicated, and the use is non-commercial. See: http:// creativecommons.org/licenses/by-nc/4.0/. 


\section{REFERENCES}

1. Amato MP, Derfuss T, Hemmer B, et al. Environmental modifiable risk factors for multiple sclerosis: Report from the 2016 ECTRIMS focused workshop. Mult Scler 2017:1-14.

2. Parisi R, Symmons DP, Griffiths CE, et al. Global epidemiology of psoriasis: a systematic review of incidence and prevalence. J Invest Dermatol 2013;133:377-85.

3. Baumgart DC, Carding SR. Gastroenterology 1: Inflammatory bowel disease: cause and immunobiology. The Lancet 2007;369:1627.

4. Baumgart DC, Sandborn WJ. Inflammatory bowel disease: clinical aspects and established and evolving therapies. The Lancet 2007;369:1641-57

5. Strober W, Fuss I, Mannon P. The fundamental basis of inflammatory bowel disease. J Clin Invest 2007;117:514-21.

6. Taurog JD, Chhabra A, Colbert RA, et al. Ankylosing spondylitis and axial spondyloarthritis. N Engl J Med 2016;374:2563-74.

7. Löfvendahl S, Theander E, Svensson Å, et al. Validity of diagnostic codes and prevalence of physician-diagnosed psoriasis and psoriatic arthritis in southern Sweden-a population-based register study. PLoS One 2014;9:e98024.

8. Christensen R, Heitmann BL, Andersen KW, et al. Impact of red and processed meat and fibre intake on treatment outcomes among patients with chronic inflammatory diseases: protocol for a prospective cohort study of prognostic factors and personalised medicine. BMJ Open 2018;8:e018166.

9. Molodecky NA, Soon IS, Rabi DM, et al. Increasing incidence and prevalence of the inflammatory bowel diseases with time, based on systematic review. Gastroenterology 2012;142:46-54.

10. Leray E, Moreau T, Fromont A, et al. Epidemiology of multiple sclerosis. Rev Neurol 2016;172:3-13.

11. Browne P, Chandraratna D, Angood C, et al. Atlas of Multiple Sclerosis 2013: A growing global problem with widespread inequity. Neurology 2014;83:1022-4.

12. $\mathrm{Ng} \mathrm{SC}$, Shi HY, Hamidi N, et al. Worldwide incidence and prevalence of inflammatory bowel disease in the 21st century: a systematic review of population-based studies. Lancet 2018;390:2769-78.

13. WHO. Chronic Diseases and Health Promotion. 2017 http://www. who.int/chp/topics/rheumatic/en/

14. Poddubnyy D, Rudwaleit M. Efficacy and safety of adalimumab treatment in patients with rheumatoid arthritis, ankylosing spondylitis and psoriatic arthritis. Expert Opin Drug Saf 2011;10:655-73.

15. Egeberg A, Skov L, Gislason GH, et al. Incidence and Prevalence of Psoriasis in Denmark. Acta Derm Venereol 2017;97:808-12.

16. Egeberg A, Kristensen LE, Thyssen JP, et al. Incidence and prevalence of psoriatic arthritis in Denmark: a nationwide register linkage study. Ann Rheum Dis 2017;76:1591-7.

17. Olivieri I, Palazzi C, Peruz G, et al. Management issues with elderlyonset rheumatoid arthritis: an update. Drugs Aging 2005;22:809-22.

18. Taleban S, Colombel JF, Mohler MJ, et al. Inflammatory bowel disease and the elderly: a review. J Crohns Colitis 2015;9:507-15.

19. Koch-Henriksen N, Thygesen LC, Stenager E, et al. Incidence of MS has increased markedly over six decades in Denmark particularly with late onset and in women. Neurology 2018;90:e1954-e1963.

20. Beecham AH, Patsopoulos NA, Xifara DK, et al. Analysis of immune-related loci identifies 48 new susceptibility variants for multiple sclerosis. Nat Genet 2013;45:1353-60.

21. Ellinghaus $D$, Jostins L, Spain SL, et al. Analysis of five chronic inflammatory diseases identifies 27 new associations and highlights disease-specific patterns at shared loci. Nat Genet 2016;48:510-8.

22. Anderson CA, Boucher $\mathrm{G}$, Lees CW, et al. Meta-analysis identifies 29 additional ulcerative colitis risk loci, increasing the number of confirmed associations to 47. Nat Genet 2011;43:246-52.

23. Ellinghaus D, Zhang H, Zeissig S, et al. Association between variants of PRDM1 and NDP52 and Crohn's disease, based on exome sequencing and functional studies. Gastroenterology 2013:145:339-47.

24. Goyette P, Boucher G, Mallon D, et al. High-density mapping of the $\mathrm{MHC}$ identifies a shared role for HLA-DRB1*01:03 in inflammatory bowel diseases and heterozygous advantage in ulcerative colitis. Nat Genet 2015;47:172-9.

25. Ananthakrishnan AN, Khalili H, Higuchi LM, et al. Higher predicted vitamin D status is associated with reduced risk of Crohn's disease. Gastroenterology 2012:142:482-9.

26. Ananthakrishnan AN, Khalili H, Konijeti GG, et al. Long-term intake of dietary fat and risk of ulcerative colitis and Crohn's disease. Gut 2014;63:776-84.

27. Ananthakrishnan AN, Khalili H, Konijeti GG, et al. A prospective study of long-term intake of dietary fiber and risk of Crohn's disease and ulcerative colitis. Gastroenterology 2013;145:970-7.
28. Ananthakrishnan $\mathrm{AN}$, Khalili $\mathrm{H}$, Song $\mathrm{M}$, et al. Zinc intake and risk of Crohn's disease and ulcerative colitis: a prospective cohort study. Int J Epidemiol 2015;44:1995-2005.

29. Ananthakrishnan $\mathrm{AN}$, Khalili $\mathrm{H}$, Song $\mathrm{M}$, et al. High School Diet and Risk of Crohn's Disease and Ulcerative Colitis. Inflamm Bowel Dis 2015;21:2311-9.

30. Chan SS, Luben R, Olsen A, et al. Association between high dietary intake of the n-3 polyunsaturated fatty acid docosahexaenoic acid and reduced risk of Crohn's disease. Aliment Pharmacol Ther 2014;39:834-42.

31. Chan SS, Luben R, Olsen A, et al. Body mass index and the risk for Crohn's disease and ulcerative colitis: data from a European Prospective Cohort Study (The IBD in EPIC Study). Am J Gastroenterol 2013;108:575-.

32. Chan SS, Luben R, van Schaik F, et al. Carbohydrate intake in the etiology of Crohn's disease and ulcerative colitis. Inflamm Bowel Dis 2014;20:2013-21.

33. John S, Luben R, Shrestha SS, et al. Dietary n-3 polyunsaturated fatty acids and the aetiology of ulcerative colitis: a UK prospective cohort study. Eur J Gastroenterol Hepatol 2010;22:602-6.

34. de Silva PS, Luben R, Shrestha SS, et al. Dietary arachidonic and oleic acid intake in ulcerative colitis etiology: a prospective cohort study using 7-day food diaries. Eur J Gastroenterol Hepatol 2014;26:11-18

35. de Silva PS, Olsen A, Christensen J, et al. An association between dietary arachidonic acid, measured in adipose tissue, and ulcerative colitis. Gastroenterology 2010;139:1912-7.

36. Hart AR, Luben R, Olsen A, et al. Diet in the aetiology of ulcerative colitis: a European prospective cohort study. Digestion 2008;77:57-64.

37. Opstelten JL, Leenders M, Dik VK, et al. Dairy Products, Dietary Calcium, and Risk of Inflammatory Bowel Disease: Results From a European Prospective Cohort Investigation. Inflamm Bowel Dis 2016;22:1403-11.

38. Bordoni A, Danesi F, Dardevet D, et al. Dairy products and inflammation: a review of the clinical evidence. Crit Rev Food Sci Nutr 2017;57:2497-525.

39. Lahiri M, Luben RN, Morgan C, et al. Using lifestyle factors to identify individuals at higher risk of inflammatory polyarthritis (results from the European Prospective Investigation of CancerNorfolk and the Norfolk Arthritis Register-the EPIC-2-NOAR Study). Ann Rheum Dis 2014;73:219-26.

40. Pattison DJ, Symmons DP, Lunt M, et al. Dietary risk factors for the development of inflammatory polyarthritis: evidence for a role of high level of red meat consumption. Arthritis Rheum 2004;50:3804-12.

41. Lauer K. Multiple sclerosis in relation to meat preservation in France and Switzerland. Neuroepidemiology 1989;8:308-15

42. Lauer K. The food pattern in geographical relation to the risk of multiple sclerosis in the Mediterranean and Near East region. $J$ Epidemiol Community Health 1991;45:251-2.

43. Lauer K. Notes on the epidemiology of multiple sclerosis, with special reference to dietary habits. Int J Mol Sci 2014;15:3533-45.

44. Lauer K. The history of nitrite in human nutrition: a contribution from German cookery books. J Clin Epidemiol 1991;44:261-4.

45. Sharif K, Watad A, Bragazzi NL, et al. Physical activity and autoimmune diseases: Get moving and manage the disease. Autoimmun Rev 2018;17:53-72.

46. Jones PD, Kappelman MD, Martin CF, et al. Exercise decreases risk of future active disease in patients with inflammatory bowel disease in remission. Inflamm Bowel Dis 2015;21:1063-71.

47. Bilski J, Mazur-Bialy Al, Wierdak M, et al. The impact of physical activity and nutrition on inflammatory bowel disease: the potential role of cross talk between adipose tissue and skeletal muscle. $J$ Physiol Pharmacol 2013;64:143-55.

48. Wolk K, Mallbris L, Larsson P, et al. Excessive body weight and smoking associates with a high risk of onset of plaque psoriasis. Acta Derm Venereol 2009;89:492-7.

49. Oliver JE, Silman AJ. Risk factors for the development of rheumatoid arthritis. Scand J Rheumatol 2006;35:169-74.

50. Mahid SS, Minor KS, Soto RE, et al. Smoking and inflammatory bowel disease: a meta-analysis. Mayo Clin Proc 2006;81:1462-71.

51. Klareskog L, Malmström V, Lundberg K, et al. Smoking, citrullination and genetic variability in the immunopathogenesis of rheumatoid arthritis. Semin Immunol 2011;23:92-8.

52. Li W, Han J, Choi HK, et al. Smoking and risk of incident psoriasis among women and men in the United States: a combined analysis. Am J Epidemiol 2012;175:402-13.

53. Costenbader KH, Feskanich D, Mandl LA, et al. Smoking intensity, duration, and cessation, and the risk of rheumatoid arthritis in women. Am J Med 2006;119:503.e1-503.e9. 
54. Setty AR, Curhan G, Choi HK. Smoking and the risk of psoriasis in women: Nurses' Health Study II. Am J Med 2007;120:953-9.

55. Alfredsson L, Olsson T. Lifestyle and Environmental Factors in Multiple Sclerosis. Cold Spring Harb Perspect Med 2018:a028944 (published Online First: 2018/05/08)

56. Palacios N, Alonso A, Brønnum-Hansen $\mathrm{H}$, et al. Smoking and increased risk of multiple sclerosis: parallel trends in the sex ratio reinforce the evidence. Ann Epidemiol 2011;21:536-42.

57. Swanson GR, Sedghi S, Farhadi A, et al. Pattern of alcohol consumption and its effect on gastrointestinal symptoms in inflammatory bowel disease. Alcohol 2010;44:223-8.

58. Khasawneh M, Spence AD, Addley J, et al. The role of smoking and alcohol behaviour in the management of inflammatory bowel disease. Best Pract Res Clin Gastroenterol 2017;31:553-9.

59. Abdollahpour I, Nedjat S, Mansournia MA, et al. Lifestyle factors and multiple sclerosis: A population-based incident case-control study. Mult Scler Relat Disord 2018;22:128-33.

60. Kelly KR, Haus JM, Solomon TP, et al. A low-glycemic index diet and exercise intervention reduces TNF(alpha) in isolated mononuclear cells of older, obese adults. J Nutr 2011;141:1089-

61. Andersen V, Hansen AK, Heitmann BL. Potential Impact of Diet on Treatment Effect from Anti-TNF Drugs in Inflammatory Bowel Disease. Nutrients 2017:9:286.

62. Vieira AT, Castelo PM, Ribeiro DA, et al. Influence of Oral and Gut Microbiota in the Health of Menopausal Women. Front Microbiol 2017;8.

63. Tjønneland A, Olsen A, Boll K, et al. Study design, exposure variables, and socioeconomic determinants of participation in Diet, Cancer and Health: a population-based prospective cohort study of 57,053 men and women in Denmark. Scand J Public Health 2007;35:432-41.

64. Würtz AM, Hansen MD, Tjønneland A, et al. Substitution of meat and fish with vegetables or potatoes and risk of myocardial infarction. Br J Nutr 2016;116:1602-10

65. Sørensen M, Autrup H, Olsen A, et al. Prospective study of NAT1 and NAT2 polymorphisms, tobacco smoking and meat consumption and risk of colorectal cancer. Cancer Lett 2008;266:186-93.

66. Egeberg R, Olsen A, Christensen J, et al. Associations between red meat and risks for colon and rectal cancer depend on the type of red meat consumed. J Nutr 2013;143:464-72.

67. Charlson ME, Pompei P, Ales KL, et al. A new method of classifying prognostic comorbidity in longitudinal studies: development and validation. J Chronic Dis 1987;40:373-83.

68. Quan H, Li B, Couris CM, et al. Updating and validating the Charlson comorbidity index and score for risk adjustment in hospital discharge abstracts using data from 6 countries. Am J Epidemiol 2011;173:676-82.

69. Stata Statistical Software [program]. 15 version, 2017.

70. Mason K, Thygesen LC, Stenager E, et al. Evaluating the use and limitations of the Danish National Patient Register in register-based research using an example of multiple sclerosis. Acta Neurol Scand 2012;125:213-7.

71. Lophaven SN, Lynge E, Burisch J. The incidence of inflammatory bowel disease in Denmark 1980-2013: a nationwide cohort study. Aliment Pharmacol Ther 2017;45:961-72.

72. Kingwell E, Marriott JJ, Jetté N, et al. Incidence and prevalence of multiple sclerosis in Europe: a systematic review. BMC Neurol 2013;13:128.

73. Bentzen J, Flachs EM, Stenager E, et al. Prevalence of multiple sclerosis in Denmark 1950-2005. Mult Scler 2010;16:520-5.

74. Koch-Henriksen N, Magyari M, Laursen B. Registers of multiple sclerosis in Denmark. Acta Neurol Scand 2015;132:4-10.

75. Society TDMS. Fakta om sclerose 2013. https://scleroseforeningen. $\mathrm{dk} /$ viden-og-nyt/hvad581 er-sclerose/fa-alle-tallene-om-sclerose (accessed May 2018).

76. Kiadaliri AA, Kristensen LE, Englund M. Burden of rheumatoid arthritis in the Nordic region, 1990-2015: a comparative analysis using the Global Burden of Disease Study 2015. Scand J Rheumatol 2018;47:1-101.

77. Pedersen JK, Svendsen AJ, Hørslev-Petersen K. Incidence of Rheumatoid Arthritis in the Southern part of Denmark from 1995 to 2001. Open Rheumatol J 2007;1:18-23.

78. Pedersen CB. The Danish Civil Registration System. Scand J Public Health 2011;39:22-5.

79. Schmidt M, Schmidt SA, Sandegaard JL, et al. The Danish National Patient Registry: a review of content, data quality, and research potential. Clin Epidemiol 2015;7:449-90.

80. Pottegård A, Schmidt SAJ, Wallach-Kildemoes $\mathrm{H}$, et al. Data Resource Profile: The Danish National Prescription Registry. Int $J$ Epidemiol 2017;46:dyw213.
81. Helweg-Larsen K. The Danish Register of Causes of Death. Scand J Public Health 2011:39:26-9.

82. Ibfelt EH, Sørensen J, Jensen DV, et al. Validity and completeness of rheumatoid arthritis diagnoses in the nationwide DANBIO clinical register and the Danish National Patient Registry. Clin Epidemiol 2017;9:627-32.

83. Lindhardsen J, Gislason GH, Jacobsen S, et al. Non-steroidal antiinflammatory drugs and risk of cardiovascular disease in patients with rheumatoid arthritis: a nationwide cohort study. Ann Rheum Dis 2014;73:1515-21.

84. European prospective investigation into cancer and nutrition $\mathrm{E}$. EPIC Study 2014 http://epic.iarc.fr/ (accessed March 2018).

85. Racine A, Carbonnel F, Chan SS, et al. Dietary Patterns and Risk of Inflammatory Bowel Disease in Europe: Results from the EPIC Study. Inflamm Bowel Dis 2016;22:345-54.

86. Togo P, Heitmann BL, Sørensen TI, et al. Consistency of food intake factors by different dietary assessment methods and population groups. Br J Nutr 2003;90:667-78.

87. Tjønneland A, Overvad K, Haraldsdóttir J, et al. Validation of a semiquantitative food frequency questionnaire developed in Denmark. Int J Epidemiol 1991;20:906-12.

88. Osler M, Heitmann BL. The validity of a short food frequency questionnaire and its ability to measure changes in food intake: a longitudinal study. Int J Epidemiol 1996;25:1023-9.

89. Køster-Rasmussen R, Siersma V, Halldorsson TI, et al. Missing portion sizes in FFQ-alternatives to use of standard portions. Public Health Nutr 2015;18:1914-21.

90. Tjonneland A, Haraldsdóttir J, Overvad K, et al. Influence of individually estimated portion size data on the validity of a semiquantitative food frequency questionnaire. Int J Epidemiol 1992;21:770-7.

91. Feskanich D, Rimm EB, Giovannucci EL, et al. Reproducibility and validity of food intake measurements from a semiquantitative food frequency questionnaire. J Am Diet Assoc 1993;93:790-6.

92. Hunter DJ, Sampson L, Stampfer MJ, et al. Variability in portion sizes of commonly consumed foods among a population of women in the United States. Am J Epidemiol 1988;127:1240-9.

93. Andersen V, Chan S, Luben R, et al. Fibre intake and the development of inflammatory bowel disease: A European prospective multi-centre cohort study (EPIC-IBD). J Crohns Colitis 2018;12:129-36.

94. Goldbohm RA, van 't Veer P, van den Brandt PA, et al. Reproducibility of a food frequency questionnaire and stability of dietary habits determined from five annually repeated measurements. Eur J Clin Nutr 1995;49:420-9.

95. Johnsen NF, Christensen J, Thomsen BL, et al. Physical activity and risk of colon cancer in a cohort of Danish middle-aged men and women. Eur J Epidemiol 2006;21:877-84.

96. uk biobank. Improving the health of future generations http://www. ukbiobank.ac.uk/ (accessed May 2018).

97. Andersen V, Vogel U. Dietary fibres and meat in relation to Colorectal Cancer. Norske Gastroenterologisk Forening-nytt 2014;21:34-6.

98. Devkota S, Wang Y, Musch MW, et al. Dietary-fat-induced taurocholic acid promotes pathobiont expansion and colitis in II10/- mice. Nature 2012;487:104-8.

99. Strober W. Vitamin A rewrites the ABCs of oral tolerance. Mucosal immunology 2008;1:92-5.

100. Agmon-Levin N, Theodor E, Segal RM, et al. Vitamin D in systemic and organ-specific autoimmune diseases. Clinical reviews in allergy \& immunology 2013;45:256-66.

101. Kaulmann A, Bohn T. Carotenoids, inflammation, and oxidative stress-implications of cellular signaling pathways and relation to chronic disease prevention. Nutr Res 2014;34:907-29.

102. Ejsing-Duun M, Josephsen J, Aasted B, et al. Dietary gluten reduces the number of intestinal regulatory $T$ cells in mice. Scandinavian journal of immunology 2008;67:553-9.

103. Campbell DJ, Koch MA. Phenotypical and functional specialization of FOXP3+ regulatory T cells. Nat Rev Immunol 2011;11:119-30.

104. Pedros C, Duguet F, Saoudi A, et al. Disrupted regulatory T cell homeostasis in inflammatory bowel diseases. World J Gastroenterol 2016;22:974-95.

105. Yao CK, Muir JG, Gibson PR. Review article: insights into colonic protein fermentation, its modulation and potential health implications. Aliment Pharmacol Ther 2016;43:181-96.

106. Rooks MG, Garrett WS. Gut microbiota, metabolites and host immunity. Nat Rev Immunol 2016;16:341-52.

107. Desai MS, Seekatz AM, Koropatkin NM, et al. A Dietary FiberDeprived Gut Microbiota Degrades the Colonic Mucus Barrier and Enhances Pathogen Susceptibility. Cell 2016;167:1339-53. 
108. Png CW, Lindén SK, Gilshenan KS, et al. Mucolytic bacteria with increased prevalence in IBD mucosa augment in vitro utilization of mucin by other bacteria. Am J Gastroenterol 2010;105:2420-8.

109. Windey K, De Preter V, Louat T, et al. Modulation of protein fermentation does not affect fecal water toxicity: a randomized cross-over study in healthy subjects. PLoS One 2012;7:e52387.

110. ljssennagger N, van der Meer R, van Mil SWC. Sulfide as a Mucus Barrier-Breaker in Inflammatory Bowel Disease? Trends Mol Med 2016;22:190-9.

111. Gibson GR, Macfarlane GT, Cummings JH. Sulphate reducing bacteria and hydrogen metabolism in the human large intestine. Gut 1993;34:437-9.
112. Maloy KJ, Powrie F. Intestinal homeostasis and its breakdown in inflammatory bowel disease. Nature 2011;474:298-306.

113. Cui J, Chen Y, Wang HY, et al. Mechanisms and pathways of innate immune activation and regulation in health and cancer. Hum Vaccin Immunother 2014;10:3270-85.

114. Jia W, Whitehead RN, Griffiths L, et al. Diversity and distribution of sulphate-reducing bacteria in human faeces from healthy subjects and patients with inflammatory bowel disease. FEMS Immunol Med Microbiol 2012;65:55-68.

115. Larsen L, Jensen MD, Larsen MD, et al. The Danish National Registry for Biological Therapy in Inflammatory Bowel Disease. Clin Epidemiol 2016;8:607-12. 